\title{
The rediscovery of the Redwood orpiment and a cocktail of plants macerates containing arbutin to defeat the Arribas-Silvestre's syndrome in a bien agée upper class lady
}

\section{Lorenzo Martini}

University of Siena, Department of Pharmaceutical Biotechnologies, Via A. Moro 2, 53100 Siena, Italy

Corresponding author: Lorenzo Martini, M.Sc. E-mail: martinil163@libero.it

\begin{abstract}
The Arribas-Silvestre's syndrome is a sort of photodermatitis induced especially in elder (especially women) when they use to put pure essences or fragrances directly onto their skin, take some medicaments and expose to sun rays periodically. The black spots are irreversible and are aesthetically unpleasant. Generally people tend to renounce to treat this disease, since it seems no remedy is available and strongest lotions or emulsions containing 2-5\% of hydroquinone are banished and anyway perilous. Here I herald a simplest method using on alternate days an ancient orpiment to abrade black spots and a mix of herb macerates containing arbutin, apt to bleach the original brownish or black maculae.Results are amazing.
\end{abstract}

Key words: Arribas-Silvestre's syndrome, photodermatitis, fragrances, arbutin, Felix von Luschan's chromatic scale

\section{INTRODUCTION}

Several factors can make human skin sensitive to UV rays, including having an inherited tendency to photosensitivity, taking certain medications, or being exposed to plants in the Apiaceae or Umbelliferae family, including weeds and edible plants, such as hogweed, cowbane, carrot, parsnip, dill, fennel, celery, and anise [1-6].

Photodermatitis can have several causes, including:

- Diseases, such as lupus or eczema, that also make skin sensitive to light,

- Genetic or metabolic factors (inherited diseases or conditions, such as pellagra, caused by lack of niacin and vitamin B-3),

- Diseases, such as polymorphic light eruptions, characterized by sensitivity to sunlight,

- Reactions to chemicals and medications,

- Skin reactions to sun rays and chemical substances can give raise to acute or chronic diseases, but especially they can be provoked by allergens or toxic elements.

\section{For instance}

Antibiotics, such as tetracycline and sulfonamides, antifungals, such as griseofulvin, coal tar derivatives and psoralens, used topically for psoriasis, retinoids, such as tretinoin and medications containing retinoic acid, used for acne, nonsteroidal anti-inflammatory drugs (NSAIDs), chemotherapy agents, sulfonylureas, oral medications used for diabetes, antimalarial drugs, such as quinine and other medications, used to treat malaria, diuretics, antidepressants, such as the tricyclics, used for depression, antipsychotics, such as phenothiazines, anti-anxiety medications, such as benzodiazepines may all induce direct toxic effects, that yield to acute or on going (idest acute or chronic) photodermatities and these agents are to be considered toxic substances.

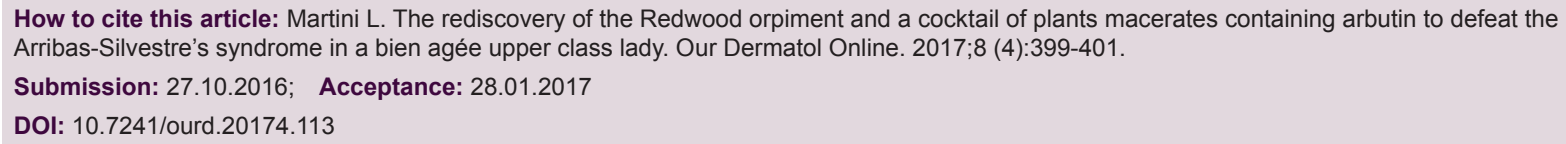


Meanwhile fragrances, sunscreens with PABA, industrial cleaners that contain salicylanilide and Concrete of Lavender may induce allergic effects, that yield to acute or on going (idest acute or chronic) photodermatities.

The irreversible skin spots evoked by fragrances, especially musk, ambrette, lemon oil, coumarins and methylcoumarins are designed under the name of Arribas-Silvestre's syndrome.

The aforesaid maculae remain throughout the entire life and are so difficult to be removed and polished, so that the man or woman who have them, is forced to renounce progressively to whichever remedy to attempt to clear his/her skin.

This case report deals of an old lady, even if fashionable, debonnaire and bien agée one, who has been putting some drops behind her ears of pure bergamot oil and other fragrances (rose églantine or civet) since very long time and presented skin spots almost remarkable, with fastidious itch and sometimes, when exposed to sun rays or during windy days, scared and pustulous maculae.

We have rediscovered the very first orpiment proposed by Dr. Redwood in 1857 [6], apt to abrade all the skin where amounts of melanin are deposited.

The recipe consists in $7 \%$ of barium sulphide in rice starch and glycerine to be gently scrubbed onto the spots.

The operation of scrubbing the orpiment must be repeated periodically, almost three times during a week, in order to have a polished skin, that must anyway clarified by the usage of a mix of selected mix of bleaching agents.

The bleaching agents are not but herbs that contain high percentages of arbutin $[7,8]$, that when in contact with the sweat of the skin, drives to hydroquinone.

The extracts of the herbs are:

- Pyrus malus peel extract,

- Arctostaphylos uva ursi leaf extract,

- Schisandra chinensis callus extract,

- and glycolic macerate of cranberry leaves.

All these extracts are dispersed in palm oil and the mix has to be shake before usage.

The mix of bleaching agents must be very soft and delicate with regards to the abraded skin and so the dynamics of treatments should follow the following schedule:

First the scrubbing by the aids of the orpiment ( 3 minutes) the night before to go to bed, thus the use of the lotion containing the bleaching agents, at the successive morning, one day of rest and after again for 6 times and so for two entire weeks.

The double treatment (use of the orpiment and after some hours the employ of the lotion) must be applied on alternate days for 14 days, and so the total applications result [7].

\section{MATERIALS AND METHODS}

We behind her ears, she was not capable to clear for years.

We gave her the Redwood's orpiment she had to scrub gently for three minutes the night before to go to bed, on alternate days and We consigned to her even the mix of glycolic extracts to bleach the "thesaurismosis" onto her skin, treatment she had to carry out the morning after.

We prayed the volunteer not to take benzodiazepines (she commonly used to take to sleep) and NSAIDs, since one week before the beginning of the treatment and to avoid the sun rays during the daylight.

Effectively we have had the chance of having 2 weeks of rain and clouds, that permitted to make our experimentations.

The entire duration of the alternate treatments was of 14 days.

After this day, skin turned out clear and safe, smooth and velvety.

Here follows the Felix von Luschan's chromatic scale $[8,9]$ (Fig. 1) and in the successive Table I refer, it is possible to notice how the values decreases day after day.

It is supposed that an old lady presents a coloured face skin that necessitates a pigmented blush that visagistes call "Rachel", that correspond to number 8.

Skin spots caused by the Arribas-Silvestre's syndrome in my case correspond to the number 29.

We repeat that the applications are only 7 in 14 days. 
www.odermatol.com

Table 1: The von Luschan's values scored at alternate day, during treatment with Redwood's orpiment and the mix of herbs containing arbutin

\begin{tabular}{lccccccc}
\hline Initial chromatic score & After $\mathbf{1}^{\text {st }}$ day & After $\mathbf{3}^{\text {rd }}$ day & After $\mathbf{5}^{\text {th }}$ day & After $\mathbf{7}^{\text {th }}$ day & After $\mathbf{9}^{\text {th }}$ day & After $\mathbf{1 1}^{\text {st }}$ day & After $^{13^{\text {rd }}}$ day \\
\hline 29 & 27 & 25 & 21 & 19 & 16 & 13 & 9
\end{tabular}

\begin{tabular}{|l|l|l|l|l|l|l|l|}
\hline & 1 & 10 & & & 19 & 28 \\
\hline & 2 & 11 & & & 20 & 29 \\
\hline & 3 & 12 & & & 21 & 30 \\
\hline & 4 & 13 & & & 22 & 31 \\
\hline & 5 & 14 & & & 23 & 32 \\
\hline & 6 & 15 & & & 24 & 33 \\
\hline & 7 & 16 & & & 25 & 34 \\
\hline & 8 & 17 & & & 26 & 35 \\
\hline & 9 & 18 & & & 27 & 36 \\
\hline
\end{tabular}

Figure 1: Felix von Luschan's chromatic scale.

\section{RESULTS}

In Table I the values of the decrease of the colour of the F.van Luschan's scale are plotted, considering the day of treatment.

These values overlook concerns of generic skin chromatism but keeps indeed on account the fact that old people generally present a skin sometimes yellowish or greyish.

\section{CONCLUSIONS}

It is not really possible to define a statistical behaviour of the lowering of the intensity of the amount of melanin, during the entire treatment, even if the results are quite satisfactory.

\section{REFERENCES}

1. Arribas MP, Soro P, Silvestre JF. Dermatitis de contacto alérgica por fragancias. Parte I: Actas Dermosifiliogr. 2012;103:874-9.

2. American Academy of Dermatology (AAD). Allergies: The Culprit Could Be Hiding In Your Cosmetic Bag. 2000.

3. Cosmetics Ingredient Review (CIR). 2003 CIR Compendium, containing abstracts, discussions, and conclusions of CIR cosmetic ingredient safety assessments. 2003. Washington DC.

4. de Groot AC, Frosch PJ. Adverse reactions to fragrances. A clinical review. Contact Dermatitis. 1997;36:57-86.

5. Food and Drug Administration (FDA). How to Report Problems With Products Regulated by FDA 2004.

6. Piesse GWS: Chymical, Natural and Physical Magic. Intended For The Instruction And Entertainment Of Juveniles. Longman, Brown, Green, Longmans \& Roberts, 1859. p. 201.

7. Dusková J, Dusek J, Jahodár L, Poustka F. Arbutin, salicin: the possibilities of their biotechnological production;. Ceska Slov Farm. 2005;54:78-81.

8. O'Donoghue, JL. Hydroquinone and its analogues in dermatology - a risk-benefit viewpoint. J Cosmet Dermatol. 2006;5:196-203.

9. Jablonski N, Ed Muehlenbein. Human Evolutionary Biology. Cambridge University Press. 2010.p. 177.

Copyright by Lorenzo Martini. This is an open-access article distributed under the terms of the Creative Commons Attribution License, which permits unrestricted use, distribution, and reproduction in any medium, provided the original author and source are credited.

Source of Support: Nil, Conflict of Interest: None declared. 